\title{
USE OF CERVICAL VERTEBRAL DIMENSIONS FOR ASSESSMENT OF CHILDREN GROWTH
}

\author{
Maria de Paula CALDAS ${ }^{1}$, Gláucia Maria Bovi AMBROSANO ${ }^{2}$, Francisco HAITER-NETO
}

1- DDS, MSc, Division of Oral Diagnosis, Dental School of Piracicaba / State University of Campinas, Piracicaba, SP, Brazil.

2- AGR ENG, MSc, PhD, Full Professor, Department of Community Dentistry, Dental School of Piracicaba / State University of Campinas,

Piracicaba, SP, Brazil

3- DDS, MSc, PhD, Chairman, Division of Oral Diagnosis, Dental School of Piracicaba / State University of Campinas, Piracicaba, SP, Brazil.

Corresponding address: Francisco Haiter Neto - Av. Limeira, 901 - 13414-903 - Piracicaba, SP, Brasil - Phone: $55192106-5327$ -

Fax: 5519 2106-5218 - e-mail: haiter@fop.unicamp.br

Received: December 05, 2006 - Modification: February 09, 2007 - Accepted: April 10, 2007

\begin{abstract}
$O$

bjective: The purpose of this study was to investigate whether skeletal maturation using cephalometric radiographs could be used in a Brazilian population. Material and Methods: The study population was selected from the files of the Oral Radiological Clinic of the Dental School of Piracicaba, Brazil and consisted of 128 girls and 110 boys (7.0 to 15.9 years old) who had cephalometric and hand-wrist radiographs taken on the same day. Cervical vertebral bone age was evaluated using the method described by Mito and colleagues in 2002. Bone age was assessed by the Tanner-Whitehouse (TW3) method and was used as a gold standard to determine the reliability of cervical vertebral bone age. An analysis of variance and Tukey's posthoc test were used to compare cervical vertebral bone age, bone age and chronological age at 5\% significance level. Results: The analysis of the Brazilian female children data showed that there was a statistically significant difference $(p<0.05)$ between cervical vertebral bone age and chronological age and between bone age and chronological age. However no statistically significant difference $(\mathrm{p}>0.05)$ was found between cervical vertebral bone age and bone age. Differently, the analysis of the male children data revealed a statistically significant difference $(\mathrm{p}<0.05)$ between cervical vertebral bone age and bone age and between cervical vertebral bone age and chronological age $(p<0.05)$. Conclusions: The findings of the present study suggest that the method for objectively evaluating skeletal maturation on cephalometric radiographs by determination of vertebral bone age can be applied to Brazilian females only. The development of a new method to objectively evaluate cervical vertebral bone age in males is needed.
\end{abstract}

Uniterms: Cervical vertebrae; Growth; Orthodontics; Radiography.

\section{INTRODUCTION AND LITERATURE REVIEW}

Orthodontic diagnosis and treatment planning for growth children must involve growth prediction ${ }^{6}$. The pubertal growth spurt is considered to be an advantageous period for certain types of orthodontic treatment and should be taken into account together with orthodontic treatment planning ${ }^{13}$.

Because of the wide individual variation in the timing of the pubertal growth spurt, chronological age is an unreliable guide for assessment of children development status ${ }^{5}$. Other parameters, such as growth velocity, secondary sex changes, dental development and skeletal ossification, have proven to be more accurate ${ }^{17}$.

The standard method to evaluate skeletal maturity has been the use of hand-wrist radiographs, matching the overall pattern of the subject's maturation to a set of reference patterns, available in an atlas ${ }^{9,15}$. Skeletal maturation is generally determined by evaluating either the stage of ossification of bones of the hand and wrist, due to the large number of different types of bones available in these areas, or the ossification onset of the ulnar sesamoid ${ }^{7}$. However, to avoid taking additional radiographs, the cervical vertebrae, as seen on routine lateral cephalograms, have been used to determine the skeletal maturity ${ }^{11,14,18}$.

It is well known that the lateral view of cervical vertebral bodies changes with growth. In 1972, Lamparski ${ }^{14}$ stated that the cervical vertebrae were as statistically and clinically reliable in assessing skeletal age as the hand-wrist technique ${ }^{10}$. In recent years, evaluation of cervical vertebrae has been increasingly used to determine skeletal maturation. Several authors ${ }^{4,9-11,18}$ have reported a high correlation between cervical vertebrae maturation and skeletal maturation of the hand-wrist. It has been found that cervical vertebrae could offer an alternative method for assessing maturity without the need of hand-wrist radiographs. However, cervical 
vertebrae were used to evaluate growth in a subjective manner because the method consisted of a qualitative comparison between the patient radiographs and the images contained in the atlas.

Mito, et al. ${ }^{16}(2002)$ established a new method for objectively evaluating skeletal maturation on cephalometric radiographs. A regression formula was determined to obtain cervical vertebral bone age based on ratios of measurements of the third and fourth cervical vertebral bodies. However, the population used to derive the formula consisted of Japanese girls only.

The purpose of this study was to apply the formula developed for Japanese children to Brazilian children and determine whether skeletal maturation using cephalometric radiographs could be used in this population as well.

\section{MATERIALAND METHODS}

The study population was selected from patient files of the Oral Radiological Clinic of the Dental School of Piracicaba, Brazil. A total of 238 children (128 girls and 110 boys) aged 7.0 to 15.9 years had cephalometric and hand-wrist radiographs taken on the same day (Table 1). None of these patients presented with congenital or acquired malformations of the cervical vertebrae or hand-wrist. The research protocol was approved by the Ethics in Research Committee of the Dental School of Piracicaba and parental written informed consent was obtained for enrollment of the children in the study.

All radiographs were taken with the same $\mathrm{x}$-ray equipment at the same distance and using the same exposure factors. The hand-wrist radiographs were evaluated by the TannerWhitehouse (TW3) method, which assessed specific ossification centers of the hand and wrist (radius, ulna, and selected metacarpals and phalanges) leading to their classification into one of several stages. Scores were given to each bone stage and calculated to compute the skeletal age. Intra-operator error was calculated according to Dahlberg's formula ${ }^{3}$ using 10 cephalometric and 10 hand-wrist radiographs selected at random, which were re-assessed 10 days later. The formula for calculating cervical vertebrae bone age in Japanese people was determined by a stepwise multiple regression analysis, with chronological age as a dependent variable and ratios of measurements in the third and fourth cervical vertebral bodies as independent variables, as follows: cervical vertebral bone age $(\mathrm{CVBA})=-0.20+6.20 \times\left(\mathrm{AH}_{3} /\right.$ $\left.\mathrm{AP}_{3}\right)+5.90 \times\left(\mathrm{AH}_{4} / \mathrm{AP}_{4}\right)+4.74 \times\left(\mathrm{AH}_{4} / \mathrm{PH}_{4}\right)$, where $\mathrm{AH}$ is the anterior vertebral body height, $\mathrm{PH}$ is the posterior vertebral body height and AP is the anteroposterior vertebral body height (Figure 1).

All cephalometric radiographs were used to calculate cervical vertebral bone age, which were initially traced by hand on mate acetate film and evaluated by the same operator. Bone age was assessed by the TW3 method and was used as a gold standard to determine the reliability of cervical vertebral bone age.

Using Dahlberg's formula ${ }^{3}$ for all cephalometric and handwrist radiographs, the intra-operator error was 0.01 and 0.09 months for male and 0.02 and 0.03 months for female, respectively, indicating sufficient accuracy of the measurements.

Based on an exploratory analysis of the data and confirmation that they had a normal distribution, an analysis of variance (ANOVA) was used to compare cervical vertebral bone age, bone age and chronological age. Tukey's posthoc test was used to identify specific differences. All statistical analyses were performed using the SAS statistical software (SAS Institute Inc., Cary, NC, USA). Significance level was set at $5 \%$.

\section{RESULTS}

The analysis of Brazilian female children data showed that there was a statistically significant difference $(p<0.05)$ between cervical vertebral bone age and chronological age and between bone age and chronological age, however no significant difference $(\mathrm{p}>0.05)$ was found between cervical

TABLE 1- Composition of the female and male populations

\begin{tabular}{lllll} 
Age group (years) & \multicolumn{2}{c}{ Mean age (years) } \\
& Female & Male & Female & Male \\
\hline $7.0-7.9$ & 11 & 15 & 7.42 & 7.58 \\
$8.0-8.9$ & 19 & 10 & 8.31 & 8.58 \\
$9.0-9.9$ & 17 & 11 & 9.47 & 9.59 \\
$10.0-10.9$ & 16 & 16 & 10.43 & 10.47 \\
$11.0-11.9$ & 10 & 17 & 11.51 & 11.59 \\
$12.0-12.9$ & 15 & 10 & 12.31 & 12.44 \\
$13.0-13.9$ & 13 & 11 & 13.50 & 13.45 \\
$14.0-14.9$ & 14 & 10 & 14.49 & 14.52 \\
$15.0-15.9$ & 13 & 10 & 15.39 & 15.39 \\
Total & 128 & 110 & & \\
\hline
\end{tabular}


vertebral bone age and bone age (Table 2). On the other hand, the analysis of Brazilian male children data showed a statistically significant difference $(\mathrm{p}<0.05)$ between cervical vertebral bone age and bone age and between cervical vertebral bone age and chronological age $(p<0.05)$. It is noteworthy that no significant difference $(\mathrm{p}>0.05)$ was found between chronological age and bone age for males (Table 3 ).

\section{DISCUSSION}

Child development depends on individual differences in the magnitude of growth and time required to reach maturity. Therefore, it is very important to identify the individual maturational levels. By evaluating the maturational periods, the clinician can make a decision on the treatment procedures and timing in a very suitable way ${ }^{13}$.

It has long been recognized though that chronological age does not necessarily correlate with maturational age ${ }^{13}$. In spite of this knowledge, hand-wrist radiographs have been used for determination of children maturation and subsequent evaluation of growth potential during puberty.

The information from hand-wrist radiographs has been used in different ways to evaluate the bone age of a child. The Greulich-Pyle method ${ }^{8}$ has been criticized in that it may be difficult to decide which standard to choose because of the differential rate of maturation in different bones ${ }^{12}$. Acheson, et al. ${ }^{1}$ (1966) compared the reliability of the TannerWhitehouse method versus the Greulich-Pyle standards and concluded that a smaller inter-operator variance was found with the Greulich-Pyle method and a slightly smaller intra- operator variance with the Tanner-Whitehouse method. In this study, bone age was assessed by the Tanner-Whitehouse (TW3) method $^{20}$ and was used as a gold standard to determine

TABLE 2- Means ( \pm standard deviation) of cervical vertebral bone age, bone age and chronological age for the female population

$\begin{array}{ll}\text { Cervical vertebral bone age } & 11.6273 \pm 2.2826 \mathrm{a} \\ \text { Bone age } & 11.6693 \pm 2.9113 \mathrm{a} \\ \text { Chronological age } & 11.2978 \pm 2.5904 \mathrm{~b}\end{array}$

Different letters indicate statistically significant difference at $5 \%$ (Tukey's test).

TABLE 3- Means ( \pm standard deviation) of cervical vertebral bone age, bone age and chronological age for the male population
Different letters indicate statistically significant difference at $5 \%$ (Tukey's test).

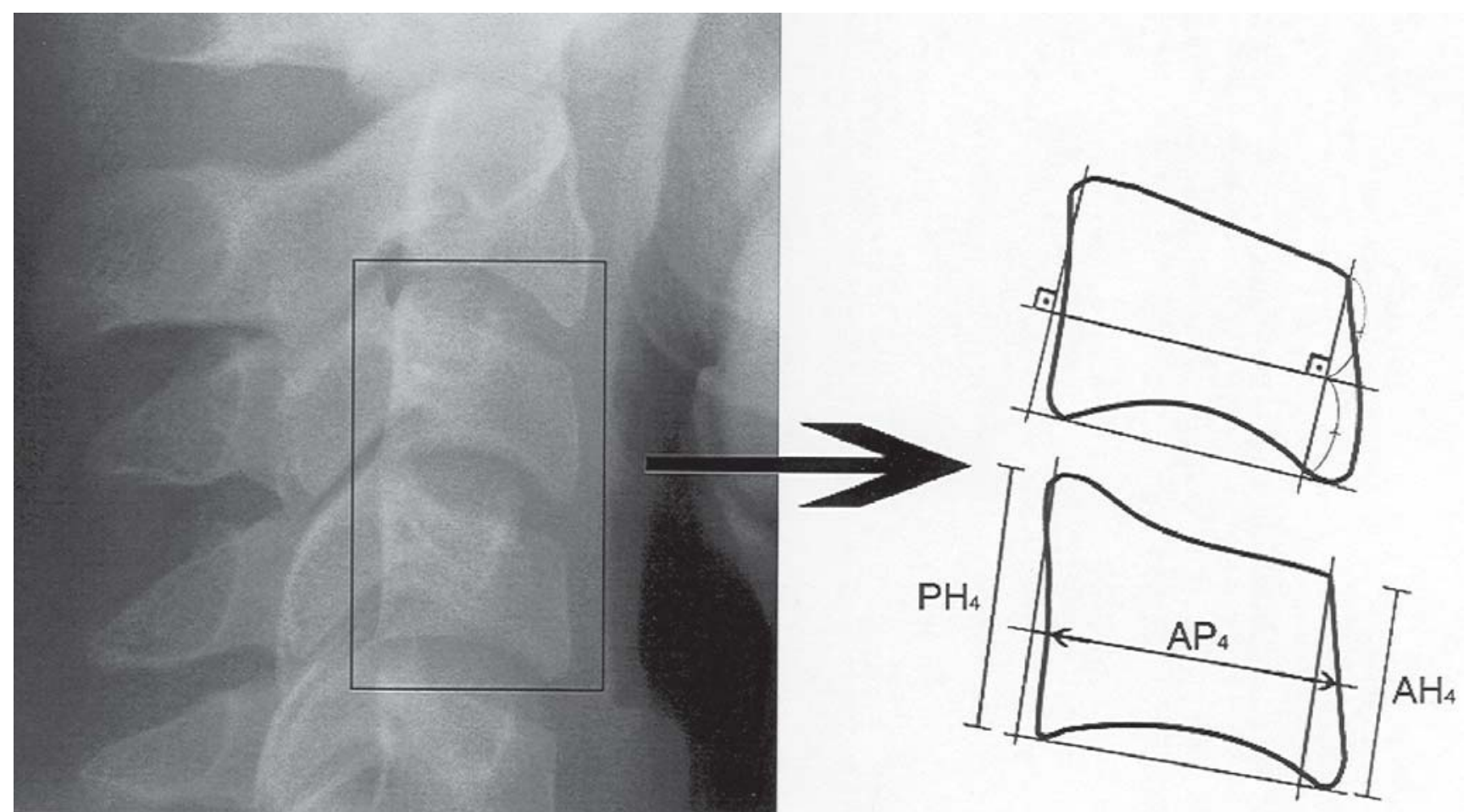

FIGURE 1- Areas of cervical vertebral bodies measured on cephalometric radiographs: $\mathrm{AH}_{4}=$ distance from the top of the front part to the tangent of the lower part; $\mathrm{PH}_{4}=$ distance from the top of the back part to the tangent of the lower part; $\mathrm{AP}_{4}=$ anteroposterior distance at the middle of the cervical vertebral body 
the reliability of cervical vertebral bone age.

Recently, the usefulness of lateral cephalometric radiographs to assess maturation has been studied ${ }^{4,9,10}$. One of the main reasons for the rising popularity of the method is that cervical vertebral maturation can be assessed on lateral cephalometric radiographs, which is a type of film used regularly in orthodontic diagnosis ${ }^{2}$. However, almost all previous evaluations with cervical vertebrae on cephalometric radiographs used the Lamparski method ${ }^{14}$, which evaluates growth in a subjective manner. This method takes into account morphological characteristics of the cervical vertebrae, as concavity of the lower border and height and shape of the vertebral bodies. The shapes of the cervical vertebral bodies of $\mathrm{C} 3$ and $\mathrm{C} 4$ change at each level of skeletal development. At first, they are wedge shaped, then changed to rectangular, next to square shape. Also, the vertical dimensions increase and inferior vertebral borders, which are flat at the beginning and become concave when they mature ${ }^{10}$.

San-Roman, et al. ${ }^{19}$ (2002) reported that the morphological vertebral parameter best able to estimate the maturation was the concavity of the lower border of the body. Therefore, concavity assessment was as accurate as the Hassel and Farman's classification, and better than Lamparski's classification to assess skeletal maturation. The parameter applied in the present study was the measurement of vertebral bodies in order to solve or at least minimize the doubts inherent to all subjective cervical vertebral maturation methods. Thus, the method developed by Mito, et al. ${ }^{16}$ (2002) used in this study was of great importance because it established a formula for objectively evaluating skeletal maturation on cephalometric radiographs. These authors ${ }^{16}$ found that cervical vertebral bone age reflects skeletal maturity because it approximates bone age. However, their study population consisted of Japanese girls only.

In the present study, we measured bodies of the third and fourth vertebrae and calculated the cervical vertebral bone age. The Japanese stepwise multiple regression showed that this formula can be used for female patients only because no statistically difference $(p>0.05)$ was found between cervical vertebral bone age and bone age. Differently, the formula cannot be used for male patients because there was a significant difference $(\mathrm{p}<0.05)$ between cervical vertebral bone age and bone age, which shows considerable sex-dependent differences in the growth patterns. A new method for objectively evaluating cervical vertebral bone age in males is already being developed by our research team.

\section{CONCLUSIONS}

The findings of the present study suggest that the method for objectively evaluating skeletal maturation on cephalometric radiographs by determination of vertebral bone age can be applied to Brazilian females only. The development of a new method to objectively evaluate cervical vertebral bone age in males is needed.

\section{REFERENCES}

1- Acheson RM, Vicinus JH, Fowler GB. Studies in the reliability of assessing skeletal maturity from x-rays. Part III. Greulich-Pyle Atlas and Tanner-Whitehouse method contrasted. Hum Biol. 1966;38:20418 .

2- Baccetti T, Franchi L, McNamara JA Jr. An improved version of the cervical vertebral maturation (CVM) method for the assessment of mandibular growth. Angle Orthod. 2002;72:316-23.

3- Dahlberg G. Statistical methods for medical and biological students. London: George Allen and Unwin Ltd; 1940.

4- Garcia-Fernandes P, Torre H, Flores L, Rea J. The cervical vertebrae as maturational indicators. J Clin Orthod. 1998;32:221-5.

5- Grave K, Townsend G. Cervical vertebral maturation as a predictor of the adolescent growth spurt. Aust Orthod J. 2003;19:25-32.

6- Grave KC. Physiological indicators in orthodontic diagnosis and treatment planning. Aust Orthod J. 1978;5:114-22.

7- Grave KC. Timing of facial growth: a study of relations with stature and ossification in the hand around puberty. Aust Orthod J. 1973;3:11722 .

8- Greulich WW, Pyle JS. Radiographic atlas of the skeletal development of the hand and wrist. Stanford: Stanford University Press; 1959.

9- Flores-Mir C, Burgess CA, Champney M, Jensen RJ, Pitcher MR, Major PW. Correlation of skeletal maturation stages determined by cervical vertebrae and hand-wrist evaluations. Angle Orthod. 2006;76:15 .

10- Hassel B, Farman AG. Skeletal maturation evaluation using cervical vertebrae. Am J Orthod Dentofacial Orthop. 1995;107:58-66.

11- Hellsing E. Cervical vertebral dimensions in 8-11, and 15-year-old children. Acta Odontol Scand. 1991;49:207-13.

12- Houston WJB. Relationships between skeletal maturity estimated from hand-wrist radiographs and the timing of the adolescent growth spurt. Eur J Orthod. 1980;2:81-93.

13- Kucukkeles N, Acar A, Biren S, Arun T. Comparisons between cervical vertebrae and hand-wrist maturation for the assessment of skeletal maturity. J Clin Pediatr Dent. 1999;24:47-52.

14- Lamparski DG. Skeletal age assessment utilizing cervical vertebrae [master's thesis]. Pittsburgh (PA): University of Pittsburgh; 1972.

15- Mitani H, Sato K. Comparison of mandibular growth with other variables during puberty. Angle Orthod. 1992;62:217-22.

16- Mito T, Sato K, Mitani H. Cervical vertebral bone age in girls. Am J Orthod Dentofacial Orthop. 2002;122:380-5.

17- Moore R, Moyer B, Dubois L. Skeletal maturation and craniofacial growth. Am J Orthod Dentofacial Orthop. 1990;98:33-40.

18- O'Reilly M, Yanniello G. Mandibular growth changes and maturation of cervical vertebrae: a longitudinal cephalometric study. Angle Orthod. 1988;58:179-84.

19- San Roman P, Palma JC, Oteo MD, Nevado E. Skeletal maturation determined by cervical vertebrae development. Eur J Orthod. 2002;24:303-11.

20- Tanner JM, Healy MJR, Goldstein H, Cameron N. Assessment of skeletal maturity and prediction of adult height (TW3 method). London: W.B. Sounders; 2001. 